Zagazig Veterinary Journal, OFaculty of Veterinary Medicine, Zagazig University, 44511, Egypt.

Volume 47, Number 1, p. 1-10, March 2019

DOI: 10.21608/zvjz.2019.5855.1006

\title{
Preparation and Evaluation of Mycoplasma gallisepticum and Mycoplasma synoviae Recombinant Vaccine
}

\author{
Sabry I. Eissa* \\ Animal Health Research Institute, Mycoplasma Department, Dokki, Giza
}

Article History: Received: 30/10/2018 Received in revised form: 15/11/2018 Accepted: 15/1/2019

\begin{abstract}
Mycoplasma gallisepticum has three virulence genes ( $m g c 1, m g c 2$ and $m g c 3$ ), and Mycoplasma synoviae has adhesion gene ( $v \operatorname{lh} A)$. These genes are responsible for adhesion and colonization of the respiratory tract of the host. Therefore, this study was concerned with preparation of recombinant vaccine from field isolates which was compared with membrane and whole cells vaccines. The virulence genes were cloned into plasmid vectors followed by transformation into E. coli BL-21competent cells for the expression of adhesion proteins. Experimental study was performed for evaluation of the prepared $M$. gallisepticum recombinant vaccine. ELISA results for Mycoplasma recombinant vaccines revealed that there was a significant difference between the vaccinated and non-vaccinated groups at $p<0.05$ for serum and egg yolk. On the other hand, results for $M$. synoviae antibody titers had no significant difference between the Geometric mean titers(GMTs) of the vaccinated groups but overall vaccinated groups had significant $(p<0.05)$ high antibody titers than the un-vaccinated group in both serum and egg yolk. Concerning the detection of mycoplasma species by polymerase chain reaction (PCR) and culture, recombinant vaccinated group were negative from the first week post-challenge till the end of experiment. While membrane and whole cell vaccinated groups gave weak positive results for $M$. gallisepticum in PCR assay and positive for culture (20\% for membrane group and $60 \%$ for whole cell group). On the other hand, $M$. synoviae was detected (20\%) by culture at one and three weeks post challenge and weak positive results was obtained by PCR till the end of experiment. The obtained results indicated that the recombinant vaccine was effective for protection of vaccinated bird against Mycoplasma infection.
\end{abstract}

Keywords: Mycoplasma gallisepticum, Mycoplasma synoviae, Cloning, Expression of adhesion proteins, Recombinant vaccine.

\section{Introduction}

Mycoplasma gallisepticum causes severe economic losses to the poultry industry. Considering that eradication through elimination of positive flocks is expensive, available vaccines do not protect against infection, and the disease is difficult to effectively treat, new alternatives are needed to control the disease [1].

M. synoviae and M. gallisepticum are avian pathogens that can both cause respiratory disturbances. In addition, M. gallisepticum infection can lead to egg production losses and M. synoviae causes articular troubles [1]. Mycoplasmas have oval, filamentous or flask shapes, and several pathogenic species display a prominent polar tip organelle or bleb structure that mediates attachment to the host target cells. With the aid of the products of the gapA(or $m g c l$ ) gene [2,3] and $\mathrm{crmA}$ or $m g c 3$ [4]. This tip structure is hemispherical, around 800x1250 $\mathrm{A}$ in circumferences and composed of surface-exposed proteins, called adhesins or cytadhesions proteins. These adhesions promote the attachment of mycoplasma allowing the colonization of epithelial cell surfaces $[5,6]$.

M. synoviae is a pathogen associated with osteoarthritis, synovitis, and respiratory tract lesions of poultry [7].Cytadherence mediated by its primary adhesion $v$ lhA that is a precursor to virulence. Posttranslational cleavage of fulllength $v$ lhA produces the peptides MSPA (carboxy-terminal portion of $v \operatorname{lh} A$ ) and MSPB

*Corresponding author e-mail: (drsabryismail@gmail.com), Animal Health Research Institute, Mycoplasma Department, Dokki, Giza. 
(amino-terminal portion). Receptor binding and cytadherence are attributed to MSPA, while the function of MSPB remains undefined [8].

As a consequence, recombinant technology could significantly help to alleviate the above mentioned drawbacks, allowing the production of unlimited amounts of multiple and more specific antigens [9]. Although identification of immunogenic antigens and genetic manipulations of mycoplasma in general are more laborious than any other prokaryotic genome, it is vital to successfully express $M$. gallisepticum proteins in heterologous systems such as E. coli [10].

Therefore, the present work aimed to prepare $M$. gallisepticum and $M$. synoviae recombinant vaccine to control mycoplasma infection in layers and breeders.

\section{Materials and Methods}

\section{Mycoplasma strains}

Four M. gallisepticum and two M. synoviae field strains were used in this study under accession numbers KY421064, KY421066,
KY421065, KY42106 for M. gallisepticum and KY421062 and KY421063 for $M$. synoviae in Genbank.

Reference strains: M. gallisepticum S6 and M. synoviae WVU 1853 kindly given by Prof. Dr. Steve Geary, Connecticut University, USA.

\section{Polymerase chain reaction (PCR) Amplification assays:}

PCR amplification assays were carried out using extracted DNA via DNA extraction kit(QIA Amp® DNA Mini Kit - Qiagen $\mathrm{GmbH}$, Hilden, Germany) according to the manufacturer's instructions and oligonucleotide primers targeting gapA, $m g c 2$ and crmA genes of $M$. gallisepticum $[10,11]$ and $v l h \mathrm{~A}$ gene of $M$. synoviae [12]. The primers (Table1) were synthesized by Macrogen, Company, South Korea. PCR was performed in a total reaction volume of $25 \mu \mathrm{L}$ containing $12.5 \mu \mathrm{L}$ of i-pfu PCR master mix (iNtRON, Korea), 5. $\mu \mathrm{L}$ of DNA template, 1 $\mu \mathrm{L}$ of each forward and reverse primer $(20$ pmol) and $5.5 \mu \mathrm{L}$ nuclease free water.

Table 1: M. gallisepticum and M. synoviae target genes, primer sequences and amplified product sizes used in

\begin{tabular}{|c|c|c|c|}
\hline $\begin{array}{l}\text { Mycoplasma } \\
\text { spp. }\end{array}$ & $\begin{array}{l}\text { Target } \\
\text { gene }\end{array}$ & Primer sequence $\left(5^{\prime}-3^{\prime}\right)$ & $\begin{array}{l}\text { Expected } \\
\text { product } \\
\text { size (bp) }\end{array}$ \\
\hline \multirow[t]{3}{*}{$\begin{array}{l}\text { M. } \\
\text { gallisepticum }\end{array}$} & gap $\mathrm{A}$ & $\begin{array}{l}\text { F- *CACCGCCGGA TTG ATT TGT ATG } \\
\text { R- ACT TGT TTT GTG TTT CC }\end{array}$ & 1511 \\
\hline & $\operatorname{crmA}$ & $\begin{array}{l}\mathrm{F} \text {-ACCAGGGGATCCGCTCCAGCACCAACTAAGAAAATTGA } \\
\text { R- GGGGGATCCCCTTATCGTAGAGAAGGGAGGT }\end{array}$ & 3263 \\
\hline & $m g c 2$ & $\begin{array}{l}\text { F-CACCGCTTTGTGTTCTCGGGTGCTA } \\
\text { R-CGGTGGAAAACCAGCTCTTG }\end{array}$ & 824 \\
\hline M. synoviae & $v \operatorname{lh} \mathrm{A}$ & $\begin{array}{l}\text { F-CACCCTTACAAGTACGGTGTTAAGTCATC } \\
\text { R-CGTATTTACAGCACCAGTAGTAACT }\end{array}$ & 1100 \\
\hline
\end{tabular}

* Added sequences for Topoisomerase enzyme insertion in the Topo vector

\section{Purification of PCR products and sequence analysis}

PCR products of the target genes were purified using GeneJET Genomic DNA purification kit (cat. No. K0721, Lithuania). Six purified PCR products were sequenced in GATC Biotech Company using ABI 3730xl DNA sequencer. DNA sequences were compared with those available in NCBI databases by using BLAST. Nucleotide sequence analysis was performed by MEGA5 program, product version 5.1 (www.megasoftware.net). Nucleotide sequences were deposited in the GenBank under accession numbers KY421064, KY421066, KY421065, KY42106 for MG and KY421062 and KY421063 for MS.

\section{Preparation of mycoplasma antigens}

Mycoplasma antigens were prepared according to Frey et al. [13]. M. gallisepticum 
and $M$. synoviae were grown in Frey's media for 48 hours and harvested by centrifugation at $14000 \mathrm{rpm}$ for $20 \mathrm{~min}$. The pellet was washed three times with phosphate buffered saline (PBS), pH 7.2, then re-suspended in PBS and the protein concentration was estimated as previously described [14].

\section{Membrane protein extraction}

It was carried out using ProteoJET, Fermentas, cat. No. $89842 \mathrm{X}$ according to the manufacturers' instructions.

\section{Preparation of recombinant vaccine}

The vaccine was prepared according to Griffin, 1949[15]. M. gallisepticum (gapA, $\operatorname{mgc} 2$ and $\operatorname{crm} A)$ and $M$. synoviae (vlhA) purified PCR products were cloned into plasmid vector pLUG- Prime TA-cloning Vector Kit (cat.No.11063. iNtRON, South Korea), followed by transformation into $E$.coli cells TOP10 chemically competent $E$. coli (Invitrogen cat. No. C4040-06, USA) then purified with plasmid DNA purification kit (DNA-Spin Plasmid DNA purification Kit cat. No. 17097 iNtRON, South Korea) followed by transformation into $E$. coli (BL-21chemically competent cells cat.No.CD60-China) for gene expression.

Expression of fusion proteins were induced by the addition of $1 \mathrm{mmol} / \mathrm{L}$ IPTG on Lysogeny broth and incubated at $37 \circ \mathrm{C}$ for 12 $\mathrm{h}$, then purified on a Nickel - NTA column (HisPur Ni-NTA columns, Thermo scientific, cat. No. 88225). The purified proteins were used for vaccine preparation.

\section{Vaccine evaluation}

Determination of Hydrophilic-Lipophilic Balance (HLB) value of the oil emulsion according to Cessi and Nardelli [16] and WHO [17].

\section{Physical evaluation}

Emulsion stability test was conducted using specification [18]. The Viscosity testing was carried out according to Cessi and Nardelli [16]. In brief, each $100 \mathrm{~mL}$ of the vaccine containing $9.7 \mathrm{~mL}$ span 80 (Sigma), $59 \mathrm{~mL}$ paraffin oil (Sigma) as oil phase, $1.8 \mathrm{~mL}$ tween 80 (sigma) and $29.5 \mathrm{~mL}$ PBS $(1 \mathrm{mg} / \mathrm{mL}$ membrane protein) as aqueous phase to prepare the vaccine.

\section{Sterility testing}

It was applied according to the Code of Federal Regulations "9 CFR" for detection of Bacteria, Fungi and Mycoplasma contamination.

Safety and potency test:

The challenge test was carried out according to Nicholas et al. [18].

\section{Experimental design}

Fifty female 85 days old commercial layers (ISA-Brown) were housed in cleaned, fumigated and well ventilated rooms in the central laboratory, Animal Health Research Institute, Dokki, Giza, Egypt. They were acclimatized for 2 days before the onset of the experiment. Non-medicated feed and water were provided. All Institutional and National Guidelines for the care and use of animals were followed.

The birds were screened by ELISA for detection of specific antibody titer (Mycoplasma gallisepticum cat. No. 96-65334Mycoplasma synoviae cat. No. 966536Synbiotics, USA) and PCR tests to confirm that the birds were control for avian Mycoplasma. The birds were divided into 7 groups (5 birds for each); vaccinated with ( $M$. gallisepticum recombinant (MGR), $M G$ membrane $(M G \mathrm{M}), M G$ with $M$. synoviae recombinant (MSR), MG plus $M$. synoviae membrane (MSM), $M$ gallisepticum whole cell $(M G \mathrm{~W}), M G \mathrm{~W}$ with a $M$. synoviae whole cell $(M S W)$ and non vaccinated control group. All vaccinated groups were kept in isolated unit away from the vaccinated groups. Throughout the study, birds were provided with feed and water and vitamins. The vaccines were given at two weeks old, with the corresponding vaccine for each vaccinated group with first dose $(100 \mu \mathrm{g} / \mathrm{mL}$ subcutaneous $)$, then received the second dose two weeks later. After two weeks the second dose was applied with same route and dose. After two weeks, all the nine vaccinated groups were challenged with the corresponding hot field strain of $M$. gallisepticum and $M$. synoviae $\left(10^{6} \mathrm{CFU} / \mathrm{mL}\right)$. Every two weeks blood samples, Eggs and tracheal swabs were collected till the end of experiment. 
Fifty samples from vaccinated birds and control negative were tested for detection of $M$. gallisepticum and M. synoviae antibodies using ELISA assay. Each tracheal swab was inoculated into Frey's broth and incubated at $37{ }^{\circ} \mathrm{C}$ for $24 \mathrm{~h}$ and cultured on Frey's agar for re-isolation of mycoplasma.

\section{Statistical analysis}

Two way ANOVA test was followed by the Duncan multiple range test to analyze data of ELISA test for each vaccinated group. By computing LSD (least significant difference) we could determine if there was a significant difference between groups according to IBM= SPSS 20 [19].

\section{Results}

PCR succeeded to amplify gapA, crmA and $m g c 2$ of $M$. gallisepticum; and the vlhA gene of $M$. synoviae isolated from pelleted cells of $M$. gallisepticum and M. synoviae field and reference strains. The PCR products gave the expected amplicon size as demonstrated in Figure (1). The different genes were purified and sequenced. The sequence analysis of the field strains were compared with the reference strains on GenBank Data base and showed $100 \%$ similarity.

\section{B}

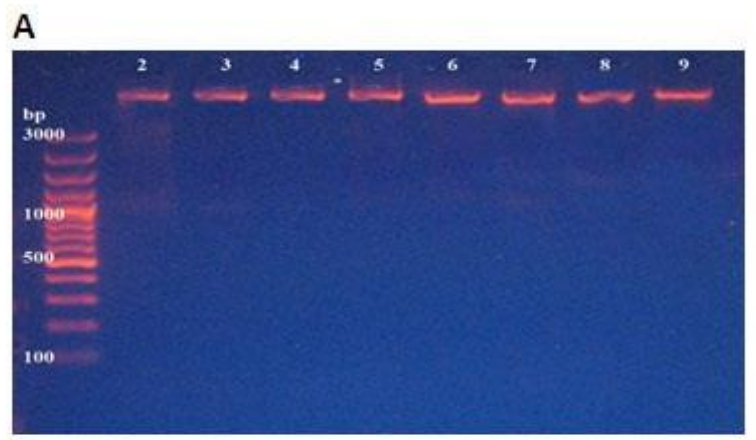

\section{B}

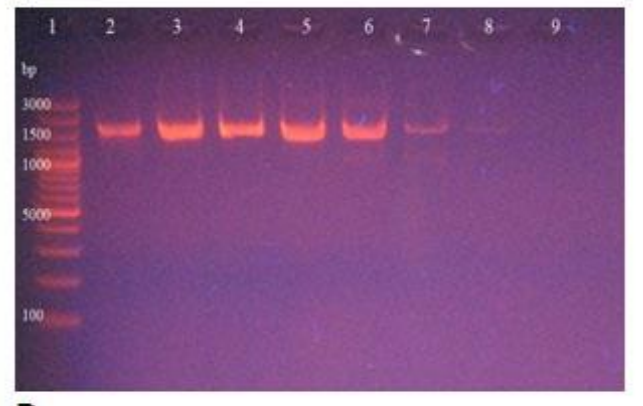

C

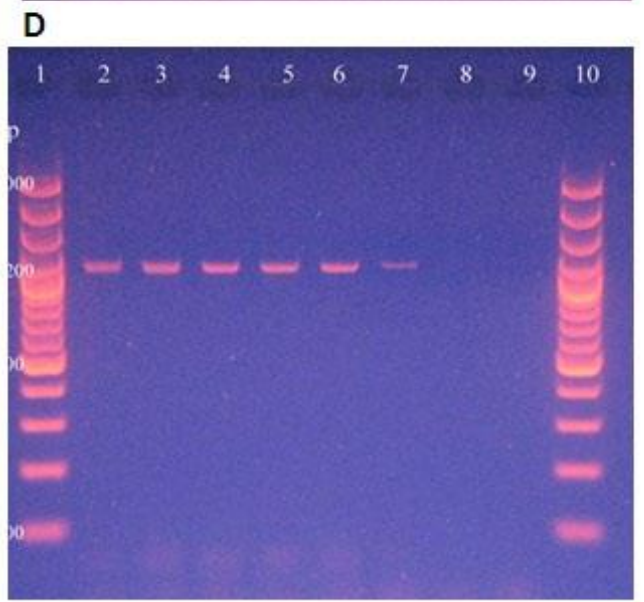

Figure 1: (A):Agarose gel electrophoresis of PCR amplified product of $\mathrm{crmA}$ gene in $M$. gallisepticum field and reference strains. Lane 1: 100 bp DNA ladder; Lane 2: reference strain; Lanes 3-9: field isolates. (B): Amplified product of gapA gene of $M$. gallisepticum reference (S6) and field strain. Lane 1: 100 bp DNA ladder; Lane 2: reference strain; Lanes 3-9: field isolates. (C): Amplified product of $m g c 2$ gene of $M$. gallisepticum reference (S6) and field strains, Lane 1: 100 bp DNA ladder; Lane 2: reference strain; Lanes 36: field isolates. (D): Amplified product of $v \operatorname{lhA}$ gene of $M$. synoviae reference and field strains, Lane 1\& 10: 100 bp DNA ladder; Lane 2: reference strain; Lanes 3-9: field isolates.

Tracheal swabs that had turned yellow on Frey's broth were subjected to DNA extraction and tested by PCR test for the detection of $M$. gallisepticum and $M$. synoviae using specific primers.
As depicted in Table (2) there was significant difference between the means of the antibodies in serum samples of different vaccinated groups $M G$ and $M S \mathrm{R}, M G$ and $M S \mathrm{M}$ and negative control group at $p<0.05$ and $p<0.01$. $M G \mathrm{R}, M G \mathrm{M}, M S$ and $M G \mathrm{~W}$ had 
significantly higher means than control negative group at $p<0.05$.

For M. gallisepticum egg yolk there was significant difference between the means of the $M G$ and $M S \mathrm{R}, M G \mathrm{~W}$ vaccinated groups and the non vaccinated birds at $p<0.05$ and $p<0.01$ but $M G \mathrm{R}, M G \mathrm{M}, M G, M S \mathrm{M}, M S$ and $M G \mathrm{~W}$ had significantly higher means than control group at $p<0.05$.
For both serum and egg yolk, all vaccinated groups had significantly higher means than the non vaccinated group at $p<0.05$.

Table (3) shows the geometric mean titers (GMTs) of M. synoviae in serum and egg yolk. The results proved that there were no significant differences between the GMTs of the vaccinated groups, but all vaccinated groups were significantly different from the control group at $p<0.05$.

Table 2: Geomeric mean titers of MG ELISA in serum and egg yolk of different vaccinated and control groups of experiment

\begin{tabular}{|c|c|c|c|c|c|c|c|}
\hline & Groups & $2^{\text {nd }}$ week & $4^{\text {th }}$ week & $6^{\text {th }}$ week & $8^{\text {th }}$ week & $10^{\text {th }}$ week & $12^{\text {th }}$ week \\
\hline \multirow[t]{7}{*}{ Serum } & MGR & $\begin{array}{l}832.5 \pm \\
164.91^{\mathrm{b}}\end{array}$ & $\begin{array}{c}994.4 \pm \\
187.33^{\mathrm{b}}\end{array}$ & $\begin{array}{l}1101.6 \pm \\
185.29^{c}\end{array}$ & $\begin{array}{l}1334.6 \pm \\
206.38^{c}\end{array}$ & $\begin{array}{l}1832.7 \pm \\
325.95^{\mathrm{d}}\end{array}$ & $\begin{array}{l}1986.7 \pm \\
354.26^{\mathrm{d}}\end{array}$ \\
\hline & MGM & $\begin{array}{l}915.1 \pm \\
169.24^{\mathrm{b}}\end{array}$ & $\begin{array}{l}1190.1 \pm \\
198.54^{\mathrm{c}}\end{array}$ & $\begin{array}{l}1217.4 \pm \\
223.87^{\mathrm{c}}\end{array}$ & $\begin{array}{l}1132.2 \pm \\
215.47^{\mathrm{c}}\end{array}$ & $\begin{array}{l}1323.5 \pm \\
216.88^{c}\end{array}$ & $\begin{array}{l}1284.8 \pm \\
248.39^{\mathrm{c}}\end{array}$ \\
\hline & MG\&MSR & $\begin{array}{l}1410.2 \pm \\
223.76^{c}\end{array}$ & $\begin{array}{l}1662.5 \pm \\
289.35^{\mathrm{d}}\end{array}$ & $\begin{array}{l}1881.3 \pm \\
342.58^{d}\end{array}$ & $\begin{array}{l}1720.9 \pm \\
339.24^{\mathrm{d}}\end{array}$ & $\begin{array}{l}2019.5 \pm \\
362.98^{d}\end{array}$ & $\begin{array}{l}2370.7 \pm \\
374.85^{\mathrm{e}}\end{array}$ \\
\hline & MG\&MSM & $\begin{array}{l}1070.6 \pm \\
164.22^{b}\end{array}$ & $\begin{array}{l}1235.2 \pm \\
218.94^{\mathrm{c}}\end{array}$ & $\begin{array}{l}1482.5 \pm \\
237.83^{c}\end{array}$ & $\begin{array}{l}1555.2 \pm \\
254.28^{d}\end{array}$ & $\begin{array}{l}1970.8 \pm \\
332.52^{d}\end{array}$ & $\begin{array}{l}2350.3 \pm \\
374.12^{\mathrm{e}}\end{array}$ \\
\hline & MGW & $\begin{array}{l}667.9 \pm \\
115.29^{\mathrm{b}}\end{array}$ & $\begin{array}{l}845.2 \pm \\
159.35^{\mathrm{b}}\end{array}$ & $\begin{array}{l}1202.4 \pm \\
241.58^{c}\end{array}$ & $\begin{array}{l}1075.8 \pm \\
168.43^{b}\end{array}$ & $\begin{array}{l}1145.3 \pm \\
191.03^{c}\end{array}$ & $\begin{array}{l}1289.1 \pm \\
222.32^{\mathrm{c}}\end{array}$ \\
\hline & MS\&MGW & $\begin{array}{l}941.5 \pm \\
166.43^{b}\end{array}$ & $\begin{array}{l}1234.4 \pm \\
254.68^{\mathrm{c}}\end{array}$ & $\begin{array}{l}1363.2 \pm \\
251.38^{\mathrm{c}}\end{array}$ & $\begin{array}{l}1641.2 \pm \\
300.68^{d}\end{array}$ & $\begin{array}{l}1580.5 \pm \\
314.58\end{array}$ & $\begin{array}{l}1663.4 \pm \\
325.98^{d}\end{array}$ \\
\hline & Control & $\begin{array}{c}48.09 \pm \\
7.24^{\mathrm{a}}\end{array}$ & $\begin{array}{c}24.82 \pm \\
4.86^{\mathrm{a}}\end{array}$ & $\begin{array}{l}59.9 \pm \\
8.89^{\mathrm{a}}\end{array}$ & $\begin{array}{c}37.12 \pm \\
6.67^{\mathrm{a}}\end{array}$ & $\begin{array}{l}43.51 \pm \\
8.54^{\mathrm{a}}\end{array}$ & $\begin{array}{l}67.61 \pm \\
11.21^{\mathrm{a}}\end{array}$ \\
\hline \multirow[t]{7}{*}{ Egg yolk } & MGR & $\begin{array}{l}480.4 \pm \\
106.31^{b}\end{array}$ & $\begin{array}{l}740.3 \pm \\
154.36^{\mathrm{c}}\end{array}$ & $\begin{array}{l}1009.4 \pm \\
173.45^{\mathrm{d}}\end{array}$ & $\begin{array}{l}814.3 \pm \\
159.52^{c}\end{array}$ & $\begin{array}{l}1201.1 \pm \\
194.67^{\mathrm{e}}\end{array}$ & $\begin{array}{l}1152.1 \pm \\
180.61^{\mathrm{e}}\end{array}$ \\
\hline & MGM & $\begin{array}{c}833.2 \pm \\
155.42^{c}\end{array}$ & $\begin{array}{c}886.5 \pm \\
152.68^{c}\end{array}$ & $\begin{array}{l}988.5 \pm \\
177.14^{\mathrm{c}}\end{array}$ & $\begin{array}{l}968.9 \pm \\
187.25^{\mathrm{c}}\end{array}$ & $\begin{array}{c}1079 \pm \\
194.22^{\mathrm{d}}\end{array}$ & $\begin{array}{l}1221.2 \pm \\
204.65^{\mathrm{e}}\end{array}$ \\
\hline & MG\&MSR & $\begin{array}{l}842.1 \pm \\
151.47^{b}\end{array}$ & $\begin{array}{l}1201.4 \pm \\
211.03^{\mathrm{e}}\end{array}$ & $\begin{array}{l}1169.9 \pm \\
189.51^{\mathrm{e}}\end{array}$ & $\begin{array}{l}1324.1 \pm \\
209.66^{\mathrm{e}}\end{array}$ & $\begin{array}{l}1581.2 \pm \\
251.96^{\mathrm{f}}\end{array}$ & $\begin{array}{l}1524.5 \pm \\
254.34^{\mathrm{f}}\end{array}$ \\
\hline & MG\&MSM & $\begin{array}{l}660.9 \pm \\
135.99^{\mathrm{b}}\end{array}$ & $\begin{array}{c}883.4 \pm \\
151.22^{c}\end{array}$ & $\begin{array}{l}1210.1 \pm \\
189.33^{\mathrm{e}}\end{array}$ & $\begin{array}{l}1257.4 \pm \\
193.21^{\mathrm{e}}\end{array}$ & $\begin{array}{l}1318.2 \pm \\
202.54^{\mathrm{e}}\end{array}$ & $\begin{array}{l}1146.9 \pm \\
180.67^{\mathrm{e}}\end{array}$ \\
\hline & MGW & $\begin{array}{l}662.01 \pm \\
128.73^{b}\end{array}$ & $\begin{array}{l}1007.5 \pm \\
168.24^{\mathrm{d}}\end{array}$ & $\begin{array}{l}1249.0 \pm \\
212.89^{\mathrm{e}}\end{array}$ & $\begin{array}{l}1422.1 \pm \\
232.14^{\mathrm{f}}\end{array}$ & $\begin{array}{l}1576.5 \pm \\
256.69^{f}\end{array}$ & $\begin{array}{c}1533.07 \pm \\
261.87^{\mathrm{f}}\end{array}$ \\
\hline & MS\&MGW & $\begin{array}{l}262.1 \pm \\
54.21^{\mathrm{ab}}\end{array}$ & $\begin{array}{l}638.7 \pm \\
118.35^{b}\end{array}$ & $\begin{array}{c}912.2 \pm \\
169.47^{b}\end{array}$ & $\begin{array}{l}1215.1 \pm \\
182.55^{\mathrm{e}}\end{array}$ & $\begin{array}{l}1379.4 \pm \\
197.03^{\mathrm{e}}\end{array}$ & $\begin{array}{l}1307.1 \pm \\
213.41^{\mathrm{e}}\end{array}$ \\
\hline & Control & $\begin{array}{l}55.66 \pm \\
10.22^{a}\end{array}$ & $\begin{array}{c}20.85 \pm \\
3.87^{\mathrm{a}}\end{array}$ & $\begin{array}{c}32.91 \pm \\
6.86^{\mathrm{a}}\end{array}$ & $\begin{array}{c}44.26 \pm \\
9.47^{\mathrm{a}}\end{array}$ & $\begin{array}{c}36.34 \pm \\
5.98^{\mathrm{a}}\end{array}$ & $\begin{array}{c}22.69 \pm \\
4.16^{\mathrm{a}}\end{array}$ \\
\hline
\end{tabular}

MGR: M. gallisepticum recombinant, MGM: MG membrane, MG\&MSR:MG with $M$. synoviae recombinant, MG\&MSM: MG plus M. synoviae membrane, MGW: M gallisepticum whole cell, MS\&MGW: M. synoviae plus $M$ gallisepticum whole cell and non vaccinated control group. Means within the same column with different superscripts are significantly different $(\mathrm{P}<0.05)$. 
Table 3: Geomeric mean titers of $M$. synoviae ELISA in serum and egg yolk of different vaccinated and control groups of experiment

\begin{tabular}{|c|c|c|c|c|c|c|c|}
\hline Type of samples & Groups & $2^{\text {nd }}$ week & $4^{\text {th }}$ week & $6^{\text {th }}$ week & $8^{\text {th }}$ week & $\begin{array}{c}1^{10^{\text {th }}} \\
\text { week }\end{array}$ & $\begin{array}{c}12^{\text {th }} \\
\text { week }\end{array}$ \\
\hline \multirow[t]{7}{*}{ Serum } & MSR & $\begin{array}{c}725.4 \pm \\
152.65^{\mathrm{b}}\end{array}$ & $\begin{array}{c}951.6^{\mathrm{b}} \pm \\
164.38\end{array}$ & $\begin{array}{c}1165.3 \\
183.79^{\mathrm{c}}\end{array}$ & $\begin{array}{l}1684.4 \pm \\
238.11^{d}\end{array}$ & $\begin{array}{l}1986.2 \pm \\
285.38^{d}\end{array}$ & $\begin{array}{l}2114.5 \pm \\
297.32^{\mathrm{e}}\end{array}$ \\
\hline & MSM & $\begin{array}{l}954.6 \pm \\
168.35^{b}\end{array}$ & $\begin{array}{l}912.3 \pm \\
167.24^{b}\end{array}$ & $\begin{array}{l}1478.1 \pm \\
224.11^{\mathrm{c}}\end{array}$ & $\begin{array}{l}2314.8 \pm \\
286.37^{\mathrm{e}}\end{array}$ & $\begin{array}{l}2264.4 \pm \\
281.44^{\mathrm{e}}\end{array}$ & $\begin{array}{l}2754.6 \pm \\
357.24^{\mathrm{f}}\end{array}$ \\
\hline & MG\&MSR & $\begin{array}{l}972.7 \pm \\
159.91^{\mathrm{b}}\end{array}$ & $\begin{array}{l}1055.6 \pm \\
163.87^{c}\end{array}$ & $\begin{array}{l}1285.7 \pm \\
182.92^{\mathrm{c}}\end{array}$ & $\begin{array}{l}2008.6 \pm \\
269.63^{d}\end{array}$ & $\begin{array}{l}1948.3 \pm \\
266.75^{\mathrm{d}}\end{array}$ & $\begin{array}{l}2338.1 \pm \\
324.21^{\mathrm{e}}\end{array}$ \\
\hline & MG\&MSM & $\begin{array}{l}872.5 \pm \\
158.35^{b}\end{array}$ & $\begin{array}{c}982.6 \pm \\
166.47^{b}\end{array}$ & $\begin{array}{l}1604.6^{ \pm} \\
241.36^{d}\end{array}$ & $\begin{array}{l}2476.8 \pm \\
316.70^{\mathrm{e}}\end{array}$ & $\begin{array}{l}2854.9 \pm \\
371.88^{f}\end{array}$ & $\begin{array}{c}2908.7 \pm \\
388.64^{f}\end{array}$ \\
\hline & MSW & $\begin{array}{l}667.6 \pm \\
152.38^{b}\end{array}$ & $\begin{array}{c}772 \pm \\
156.74^{b}\end{array}$ & $\begin{array}{l}1686.2 \pm \\
229.64^{d}\end{array}$ & $\begin{array}{l}2376.7 \pm \\
294.79^{\mathrm{e}}\end{array}$ & $\begin{array}{l}2296.2 \pm \\
271.34^{\mathrm{e}}\end{array}$ & $\begin{array}{l}2440.6 \pm \\
296.41^{\mathrm{e}}\end{array}$ \\
\hline & MS\&MGW & $\begin{array}{l}822.3 \pm \\
155.36^{b}\end{array}$ & $\begin{array}{l}970.8 \pm \\
160.21^{b}\end{array}$ & $\begin{array}{l}1592.3 \pm \\
231.10^{d}\end{array}$ & $\begin{array}{l}2434.8 \pm \\
301.59^{\mathrm{e}}\end{array}$ & $\begin{array}{l}2314.6 \pm \\
281.55^{\mathrm{e}}\end{array}$ & $\begin{array}{l}1689.6 \pm \\
234.47^{d}\end{array}$ \\
\hline & Control & $\begin{array}{c}48.09 \pm \\
7.13^{\mathrm{a}}\end{array}$ & $\begin{array}{c}24.82 \pm \\
5.22^{\mathrm{a}}\end{array}$ & $\begin{array}{l}59.9 \pm \\
9.51^{\mathrm{a}}\end{array}$ & $\begin{array}{c}37.12 \pm \\
6.12^{\mathrm{a}}\end{array}$ & $\begin{array}{c}43.51 \pm \\
6.69^{\mathrm{a}}\end{array}$ & $\begin{array}{c}67.61 \pm \\
7.74^{\mathrm{a}}\end{array}$ \\
\hline \multirow[t]{7}{*}{ Egg yolk } & $M S \mathrm{R}$ & $\begin{array}{l}662.5 \pm \\
137.77^{\mathrm{b}}\end{array}$ & $\begin{array}{l}810.4 \pm \\
149.18^{b}\end{array}$ & $\begin{array}{l}1020.8 \pm \\
172.66^{c}\end{array}$ & $\begin{array}{l}1656.4 \pm \\
251.41^{\mathrm{d}}\end{array}$ & $\begin{array}{l}2015.3 \pm \\
283.46^{d}\end{array}$ & $\begin{array}{l}2116.5 \pm \\
317.25^{\mathrm{e}}\end{array}$ \\
\hline & $M S M$ & $\begin{array}{l}447.1 \pm \\
109.24^{b}\end{array}$ & $\begin{array}{l}902.5 \pm \\
157.28^{b}\end{array}$ & $\begin{array}{l}1393.9 \pm \\
213.87^{\mathrm{c}}\end{array}$ & $\begin{array}{l}2077.5 \pm \\
292.35^{d}\end{array}$ & $\begin{array}{l}2143.2 \pm \\
327.22^{\mathrm{e}}\end{array}$ & $\begin{array}{l}2227.1 \pm \\
351.25^{\mathrm{e}}\end{array}$ \\
\hline & $M G \& M S \mathrm{R}$ & $\begin{array}{l}522.3 \pm \\
89.54^{b}\end{array}$ & $\begin{array}{l}757.4 \pm \\
117.20^{b}\end{array}$ & $\begin{array}{l}1224.6 \pm \\
174.56^{\mathrm{c}}\end{array}$ & $\begin{array}{l}1938.2 \pm \\
279.35^{\mathrm{d}}\end{array}$ & $\begin{array}{l}1852.9 \pm \\
282.21^{\mathrm{d}}\end{array}$ & $\begin{array}{l}2257.6 \pm \\
270.55^{\mathrm{e}}\end{array}$ \\
\hline & $M G \& M S M$ & $\begin{array}{l}641.2 \pm \\
121.29^{\mathrm{b}}\end{array}$ & $\begin{array}{c}741.2 \pm \\
133.84^{\mathrm{b}}\end{array}$ & $\begin{array}{l}1438.8 \pm \\
251.32^{c}\end{array}$ & $\begin{array}{l}2197.5 \pm \\
345.52^{\mathrm{e}}\end{array}$ & $\begin{array}{l}2279.6 \pm \\
362.14^{\mathrm{e}}\end{array}$ & $\begin{array}{l}2115.4 \pm \\
321.47^{\mathrm{e}}\end{array}$ \\
\hline & $M S W$ & $\begin{array}{l}736.5 \pm \\
141.25^{\mathrm{b}}\end{array}$ & $\begin{array}{l}811.7 \pm \\
156.32^{b}\end{array}$ & $\begin{array}{l}1422.3 \pm \\
242.36^{c}\end{array}$ & $\begin{array}{l}2228.4 \pm \\
292.15^{\mathrm{e}}\end{array}$ & $\begin{array}{l}2146.2 \pm \\
285.35^{\mathrm{e}}\end{array}$ & $\begin{array}{l}1960.4 \pm \\
263.19^{d}\end{array}$ \\
\hline & $M S \& M G \mathrm{~W}$ & $\begin{array}{l}548.9 \pm \\
103.54^{\mathrm{b}}\end{array}$ & $\begin{array}{l}849.2 \pm \\
167.25^{b}\end{array}$ & $\begin{array}{l}1506.2 \pm \\
225.18^{c}\end{array}$ & $\begin{array}{l}2132.2 \pm \\
299.27^{\mathrm{e}}\end{array}$ & $\begin{array}{l}2017.5 \pm \\
297.36^{d}\end{array}$ & $\begin{array}{l}2054.1 \pm \\
287.94^{\mathrm{d}}\end{array}$ \\
\hline & Control & $\begin{array}{c}41.46 \pm \\
4.25^{\mathrm{a}}\end{array}$ & $\begin{array}{c}35.53 \pm \\
6.55^{\mathrm{a}}\end{array}$ & $\begin{array}{c}15.52 \pm \\
3.27^{\mathrm{a}}\end{array}$ & $\begin{array}{l}51.4 \pm \\
6.68^{a}\end{array}$ & $\begin{array}{c}51.96 \pm \\
9.42^{\mathrm{a}}\end{array}$ & $\begin{array}{c}37.24 \pm \\
6.66^{\mathrm{a}}\end{array}$ \\
\hline
\end{tabular}

MGR: M. gallisepticum recombinant, MGM: MG membrane, MG\&MSR:MG with $M$. synoviae recombinant,

MG\&MSM: MG plus $M$. synoviae membrane, MGW: M gallisepticum whole cell, MS\&MGW: M. synoviae plus $M$ gallisepticum whole cell and non vaccinated control group. Means within the same column with different superscripts are significantly different $(\mathrm{P}<0.05)$.

Concerning PCR and culture, $M G \mathrm{R}, M G$ and MSR vaccinated groups were negative from the first week post-challenge and continued till the end of experiment. While $M G \mathrm{M}, M G$ and $M S \mathrm{M}, M G \mathrm{~W}, M G$ and $M S \mathrm{~W}$ vaccinated groups gave weak positive results with $M$. gallisepticum PCR (Figure 2) and positive for culture (20\% for membrane group and $60 \%$ for whole cell group) .
On the other hand, M. synoviae PCR and culture were positive in $M S \mathrm{M}, M S$ plus $M G \mathrm{M}$, $M S \mathrm{~W}, M S$ and $M G \mathrm{~W}$ vaccinated groups (Table3). While $M S \mathrm{R}$, and $M S$ with $M G \mathrm{R}$ vaccinated groups gave positive results (20\%) by culture at one and three weeks post challenge and gave weak positive PCR results, a week post challenge and during all the experimental periods (Figure 2). 
A

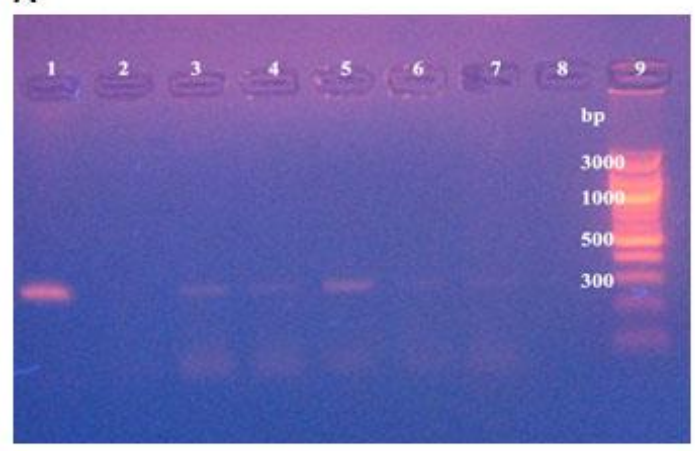

B

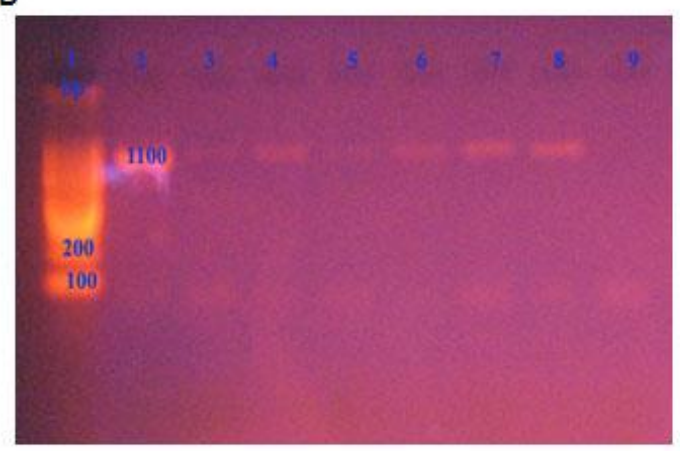

Figure 2: (A): PCR results of $M$. gallisepticum for different vaccinated groups of experiment; Lane1: Control positive, Lane 2: control negative; Lane 3: $M G \& M S$ whole cell bacterin; Lane 4: $M G$ whole cell bacterin; Lane 5: $M G \& M S$ membrane; Lane 6: $M G$ and $M S$ recombinant; Lane 7: $M G$ membrane; Lane 8: $M G$ recombinant; Lane 9: 100 bp DNA ladder. (B): PCR results of $M$. synoviae for different vaccinated groups of experiment: Lane 1: 100 bp DNA ladder; Lane 2: Control positive; Lane 3: MS recombinant; Lane 4: MS membrane; Lane 5: $M G \& M S$ recombinant; Lane 6: $M G \& M S$ membrane; Lane 7: $M S$ whole cell bacterin; Lane 8: $M G \& M S$ whole; Lane 8: $M G \& M S$ whole cell bacterin; Lane 9:non vaccinated group

\section{Discussion}

M. gallisepticum ( $\mathrm{R}$ low passage strain) is pathogenic for chickens, colonizing the trachea (during in vivo assays) and producing air sac and tracheal lesions due to presence of gapA and $\mathrm{crmA}$ genes. In contrast, $\mathrm{R}$ high strains required 4 orders of magnitude for more organisms to colonize air sacs and tracheas to produce detectable lesions [20].Also it was mentioned that $m g c 2$ gene is incorporated in cytadherence, virulence and post infection autoimmunity[21]. For M.synoviae, it was reported that $v$ lhA gene is a precursor of virulence [8]. In the present study we detected the three virulence genes of $M$. gallisepticum (gapA, crmA and $m g c 2$ ) and $v l h A$ gene of $M$. synoviae in our field strains. The purified genes were used for cloning in plasmid vector and expression in E. coli competent cells. The resulted recombinant proteins were used for preparation of recombinant vaccine. Also $M G$ and $M S$ membrane and whole cell bacterin were prepared. The obtained results proved that the recombinant vaccine can replace the other MG and MS vaccine due to good protection and healthy condition of vaccinated groups even after challenge with the virulent field strains. Besides the positive antibody titer two weeks post-vaccination and increased till the end of experiment. The results showed no significant differences among the vaccinated groups, while there was difference when compared with control negative group.
After challenge of the all vaccinated groups with MG and MS field strain, the recombinant vaccinated groups proved to be negative for PCR even at the end of experiment. On the other hand, membrane and whole cell vaccinated group showed positive PCR results.

In membrane vaccinated chickens, the antibody levels remained the same as after the challenge and the bacterin vaccinated group showed the highest titer during the entire experiment. This was found to be in agreement with Moura et al.[22] who mentioned that all vaccinated groups gave higher antibody titers and with El-Shater et al. [23] who concluded that vaccination of chickens with $M$. gallisepticum subunit vaccine resulted in high antibody response at two weeks after the booster dose.

Concerning the $M S$ vaccinated groups; recombinant vaccinated groups gave weak positive results, while membrane and whole cell vaccinated groups were positive. Trials for re-isolation of Mycoplasma from different vaccinated groups after challenge were done. $M G$ and $M G$ and $M S$ recombinant vaccinated groups and control group were negative during the experimental period, while membrane and whole cell vaccinated groups were positive, this coincides with El- Shater et al.[23]who concluded that $M$. gallisepticum subunit vaccine show humoral immunity but didn't give protection against infection, indicating 
that Mycoplasmas may have ways to overcome humoral immunity.

\section{Conclusion}

The obtained results proved that the locally prepared $M G$ and $M S$ recombinant vaccine from local field isolates was the best choice for vaccination and protection of the commercial layers against mycoplasma infection in comparison with membrane and whole cell vaccines.

\section{Conflict of interest}

The author declares that he has no conflicts of interests.

\section{Acknowledgement}

This work was supported by the project of "preparation of Mycoplasma gallisepticum and Mycoplasma synoviae recombinant vaccines to control mycoplasmosis in chickens" funded by the Science and Technology Development Fund (STDF), Egypt, Project No. 14991

\section{References}

[1]Yoder, H.W. (1991): Mycoplasma gallisepticum infection. In: Calnek, B.W.; Beard, C.W.; Barnes, H.J. and Reid, W. M. Diseases of Poultry $9^{\text {th }}$ ed. Ames/Iowa: Iowa State University Press:198-212.

[2]Goh, M.S; Gorton, T.S.; Forsyth, M.H.; Troy, K.E. and Geary, S.J. (1998): Molecular and biochemical analysis of $105 \mathrm{kDa}$ Mycoplasma gallisepticum cytadhesin (GapA). Microbiology, 144 (11):2971-2978.

[3]Keeler,, C.L.; Hantow, L.L.; Whetzel, P.L. and Dohms, J.E. (1996): Cloning and characterization of a putative cytadhesin gene $(m g c 1)$ from Mycoplasma gallisepticum. Infect Immun, 64: 1541-1547.

[4]Papazisi, L.; Troy, K.E.; Gorton, T. S.; Liao, X. and Geary, S. J. (2000): Analysis of cytadherence-deficient, GapA- control Mycoplasma gallisepticum strain R. Infect Immun, 68:6643- 6649.
[5]Dybvig, K. and Voeiker, L.L. (1996): Molecular biology of mycoplasmas. Ann Rev Microbial, 50: 25-27.

[6]Razin, S.; Yogev, D. and Naot, Y. (1998): Molecular biology and pathogenicity of mycoplasmas. Microbiol. Mol. Bio. Rev, 62:10941156.

[7]Kang, M. S. Gazdzinski, P. and S. H. Kleven. (2002): Virulence of recent isolates of Mycoplasma synoviae in turkeys. Avian Dis, 46:102-110.

[8]Noormohammadi, A. H. (2007): Role of phenotypic diversity in pathogenesis of avian mycoplasmosis. Avian Pathol, 36:439-444.

[9]Ben Abdelmoumen Mardassi, B.; B'ejaoui, A. A.; Oussaeif, L.; Mlik, B. and Amouna, F. (2008): A recombinant antigen-based ELISA for the simultaneous differential serodiagnosis of Mycoplasma gallisepticum, Mycoplasma synoviae, and Mycoplasma meleagridis infections. Avian Dis, 52:214-221.

[10]Papazisi, L.; FrascaJr, S.; Gladd, X.; Liao, X.; M.; Yogev, D. and Geary, S.J. (2002):GapA and CrmA Coexpression is essential for Mycoplasma gallisepticum Cytadherence and virulence. Infection and immunity, 70, (12): 6839-6845.

[11]Ferguson, N.M. Hepp, D.; Sun, S.; Ikuta, N.; Levisohn, S.; Kleven, L. S.H. and Garcia, M.(2005): Use of molecular diversity of Mycoplasma gallisepticum by gene-targeted sequencing (GTS) and random amplified polymorphic DNA (RAPD) analysis for epidemiological studies. Microbiol, 151: 1883-1893.

[12]Zhao, S. and Yamamoto, R. (1993): Detection of Mycoplasma synoviae by polymerase chain reaction. Avian Pathology, 22: 533-542.

[13]Frey M.C; Hanson, R.P. and Anderson, D.P. (1968): A medium for the isolation of avian 
Mycoplasma. Ann Vet Res, 29: 21642171.

[14]Bradford, M.M. (1976): A rapid and sensitive method for quantification of microgram quantities of protein using the principle of protein dye binding. Analytical Biochemistry, 72: 248254.

[15]Griffin, W. C. (1949): Classification of surface active agents by HLB. J. Soc Cosmet Chem, 1, 311-326.1949.

[16]Cessi, D. and Nardelli, L. (1974): Vaccination against Newcastle disease: efficacy of an oil emulsion vaccine. Avian Pathology, 3: 247253.

[17]World health organization. (1999): Pesticides evaluation scheme Specification-methods WHO/M/13.R4.

[18]Nicholas, R.A; Ayling, R. D. and Stipkovits, L.P. (2002): An experimental vaccine for calf pneumonia caused by Mycoplasma bovis: clinical, cultural, serological and pathological findings. Vaccine, 20: 3569-3575.

[19]IBM-SPSS(2011). IBM SPSS, Statistical package for social science. Standard version, copyright SPSS Inc., 1989 -2011, All Rights
Reserved, IBM licence, copyright ${ }^{\circledR}$ IBM \& SPSS Inc, 2011.

[20]Levisohn, S; Dykstra, M. J; Lin, M. Y. and Kleven, S. H. (1986): Comparison of in vivo and in vitro methods for pathogenicity evaluation for Mycoplasma gallisepticum in respiratory infection. Avian Pathol, 15(2):233-46.

[21]Hnatow, L.; Keeler, R; Tessmer, L.; Czymmek, K. and Dohms, J. (1998): Characterization of MGC2, a Mycoplasma gallisepticum Cytadhesin with Homology to the Mycoplasma pneumonia 30Kilodalton Protein P30 and Mycoplasma genitalium P32. Infect Immun, 66:3436-3442.

[22]Moura, L.; Dohms, J.; Almeida, J.M; Ferreira, P.S.; Biffi, C.P. and Backes, R.G. (2012): Development and evaluation of a novel subunit vaccine for Mycoplasma gallisepticum. Arq Bras Med Vet Zootec, 64, (6): 15691576.

[23]El- Shater, S.A.A.; Eissa, S.I. and Youseif, H.M.Z. (2002): Preparation of Mycoplasma gallisepticum subunit vaccine and its evaluation in chickens. Vet Med J, Giza, 50 (1): 157-169 


\section{تحضير وتقييم لقاح مؤتلف للميكوبلازما جاليسبتكم و الميكوبلازما سينوفي

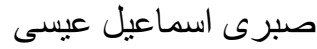 \\ معهد بحوث صحة الحيوان ـ قسم الميكوبلازما ـ الدقى - الجيزة}

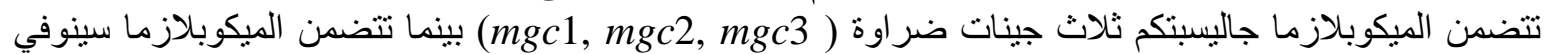

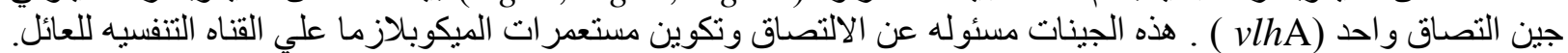

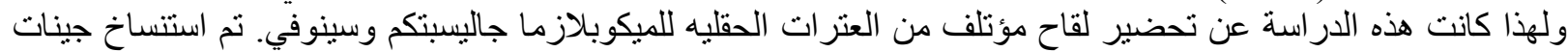

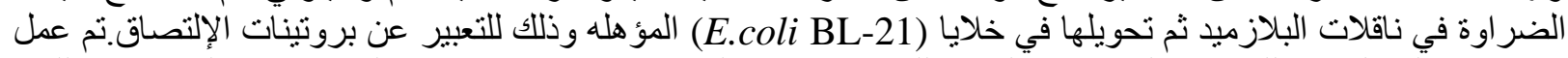

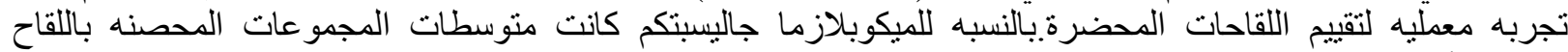

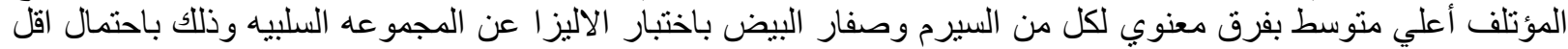

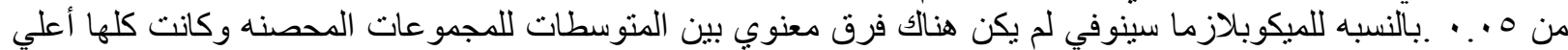

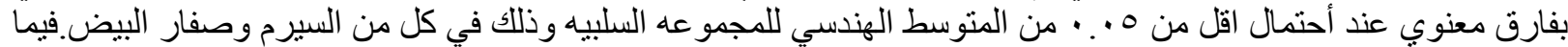

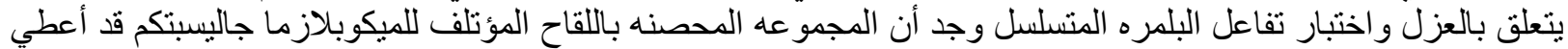

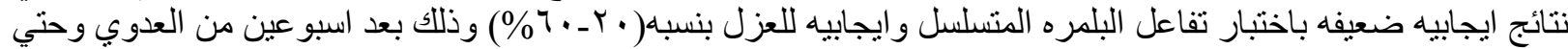

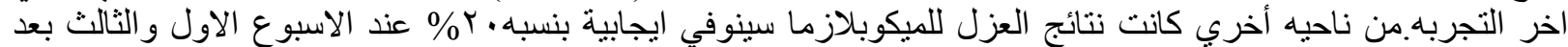

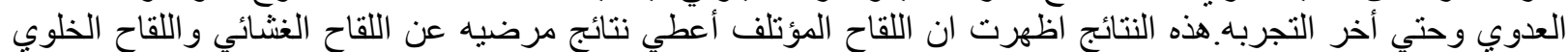

